\title{
Reducing Range Anxiety by Unifying Networks of Charging Stations
}

\author{
Khalil Salah and Nazri Kama \\ Advanced Informatics School, Universiti Teknologi Malaysia
}

\begin{abstract}
Availability of charging infrastructure is an important factor in penetration of electric vehicles into daily transportation system. Several factors in electric vehicle industry have caused range anxiety including insufficient charging stations, limited range of electric vehicles, long charging time, inaccurate estimation of available range, and energy consumption of auxiliary in-vehicle devices. However less attention has been paid to universality in charging station networks. This paper reviews the solutions to range anxiety. With regards to availability of charging station as one of the solutions, accessibility of charging stations by electric vehicle owners is also represented as another cause of range anxiety and a possible solution is provided.
\end{abstract}

\section{Introduction}

Charging Infrastructure (CI) is an important entity of power grid. Availability of this infrastructure is a key factor in general acceptance of Electric Vehicles (EV) [1]-[3]. The lack of CI as well as recharging time of an EV together with its limited range may discouraged many drivers from switching to EV [4], [5] and will lead to "Range Anxiety". Range anxiety is the fear of being left on the road with an empty battery where there is no charging station [6], [7] or lack of any CI in which the EVO has registered. Range anxiety can be considered as another impact on market acceptance of EVs [7], [8]. Therefore, availability of public CI is an important factor in penetration of EVs [1], [5], [6], [9].

In addition to the physical charging facilities, $\mathrm{CI}$ is a central communication interface among EV, Electric Vehicle Supply Equipment (EVSE), Power Grid, and energy suppliers [10], [11]. The data returning from EV through Charge Point (CP) can be used for monitoring, scheduling, energy distribution controlling during peak hours, and managing the energy consumption during offpeak hours. Therefore, a universal charging platform which is reliable and available in both public and private spots will accelerate user acceptance of EVs [1], [6], [9].

In this paper, causes and effects of range anxiety and solutions to ease this phenomenon is reviewed in section 2. Section 3 discusses on current situation of charging station networks and how to overcome range anxiety through unification of these networks. Finally, the paper is summarized by some conclusions in section 4 .

\section{Range anxiety}

CI plays an important role in development and acceptance of EVs. Accuracy and safety of its components will bring satisfaction and reliability to the industry. New techniques and technologies in design and production of battery packs and lots of research and developments funded by governments together with different Battery Management Systems (BMS) with improved calculation algorithms are the signs of the EV's desire to stay in the market.

However there is still a big obstacle against general acceptance of EVs which is uncertainty of availability of CI upon EV Owner's (EVO) demand. Considering the limited driving range of an EV compared to the conventional internal combustion engines, lack of $\mathrm{CI}$ and the long charging time of an EV can cause anxiety and stress while driving or prior to driving an EV without any auxiliary power source. This situation, which is referred to as range anxiety will affect penetration of EVs in transport system [12]-[15].

Although range anxiety was first observed in General Motor's project in 1997 [16], lots of researches have been carried out on this issue since then. Some solutions are provided in order to reduce or overcome this issue, which are described in the following sections:

\subsection{Availability of charging infrastructure}

One of the major issues which is highlighted by researches on range anxiety is lack or insufficient number of public charging stations. Although the charging process mostly happens during the night at home or in parking lots during the day, availability of public charging stations is an important factor in penetration of EVs [1], [6], [9]. Therefore deployment of widely distributed networks of fast charging stations will provide flexibility to EVOs in planning long trips [4], [5], [12], [17]-[30]. However the long charging time in compared to Internal Combustion Engines (ICE) is still an issue. 
Thus some researchers suggest to provide battery swapping stations or Charging While Driving (CWD) systems. While battery swapping might take as much time as it takes to fill the tank in ICE vehicles [27], CWD systems, in which the driver does not need to worry about charging station and spending long time to charge up the EV [31]-[35], will increase the driving range, and provide convenience and safety to EVOs. Even though the CWD system using electrified roadways and wireless power transfer methods may have a great impact on range anxiety of EVOs, until then development of current CI is required to encourage drivers to switch to EVs.

\subsection{Routing and simulating energy consumption}

Besides availability of $\mathrm{CI}$, efficient route selection can also address range anxiety [36]. In [18] the analysis of the impact of a distributed CI on the EVs range shows that daily EV's range can be extended if suitable CI exists along the planned route therefore the range anxiety can be reduced. In [36] and [17], the authors provide smartphone applications to plan efficient routes. Topography of the route, wind speed, weight of $\mathrm{EV}$, real-time road traffic, historical consumption of energy by EV, historical EVO's driving behavior, speed, temperature, operation of the air conditioner/heater, accurate State of Charge (SoC) of the battery, driving time, and the availability of CI are important factors while planning an efficient route and estimating consumption rate [17], [18], [20], [26], [36], [37].

\subsection{SoC estimation}

$\mathrm{EV}$ battery is an important element in an EV with direct effects on performance and rapid development of EVs [38]. Since batteries are sensitive to deep charge and discharge and in order to avoid it, a BMS capable of estimating accurate $\mathrm{SoC}$ is required [38]-[40].

Researchers approve that estimating the remaining power of the battery and displaying it to the user is important for effective EV use [12]-[14], [17], [20], [24][26], [30], [41]-[45]. Nevertheless, SoC and range estimation are only valid under certain conditions, therefore improvement in estimation algorithms is required to make it more accurate [20]. On the other hand in [13] the authors suggest that displaying error-prone information ambiguously might be advantageous rather than hiding them from users. In fact the knowledge of error-prone information can lead to improvements in driving experience, behavior and trust towards the EV and it might consequently decrease range anxiety.

Although displaying SoC information to $\mathrm{EVO}$ is critical, the user also needs to be informed about the appropriate methods of maximizing EV's range [29]. This can be interpreted as providing instructions to the EVO in order to adapt his/her driving style or to reduce using of auxiliary in-vehicle devices [44]. Therefore increasing actual range of an EV might be less important than providing the EVOs with reliable information [41] and educate them on how to use that information to control and manage the remaining range. For that reason in [46] and [47] the authors shows that current range of EVs might be enough for daily travels of EVOs if they understand the fact that "run-until-empty followed by a fill-up-to-full at a public gas station is not how EVs will be used". Therefore in their opinion, availability of public fast chargers might not be an issue.

\subsection{In-Vehicle energy management}

Although knowing the SoC and planning a suitable route with public fast charging stations might make the EVO convenient enough to drive an $\mathrm{EV}$, researchers suggest to improve the efficiency of in-vehicle components and manage the energy consumption in order to maximize the global efficiency, minimize energy loss, extend the range, and reduce range anxiety [30], [43], [48]-[50]. While invehicle energy management might help, using of range extenders is also considered as another solution for reducing range anxiety [15], [51]-[54].

\section{Discussion}

Despite the rapid growth in EV industry, a few studies were conducted on optimization of charging networks to reduce cost of charging station selection [55]. In a network of charging station, the satisfaction level of the EVOs relies on the appropriate location of charging station, availability of the service when it is required, cost, and timing of getting the service [56], [57].

In the current charging station networks, before the EVOs start the charging process, they need to be identified and when the charging finished, billing and payment information will be sent to them. Therefore the charging station is only accessible by the users who have already subscribed to that network. This will cause isolation in network of charging stations and consequently bring up range anxiety.

To reduce range anxiety, improvements in all areas are required. Even though an accurate SoC estimation and displaying the real SoC might help the EVOs to adapt their driving style with the remaining power, and also choosing the most efficient route might extend the driving range, the EVOs have to have access to charging stations whenever they need one.

However, availability of charging stations is not a solution to range anxiety unless the stations are universally standardized. As mentioned earlier current charging networks only provide facilities to their own registered users. Therefore when the EVOs want to plan a trip there will be another question besides "Is there any charging station?" which is: "Can I use that charging station?"

Today most of the charging stations are using Open Charge Point Protocol (OCPP) as the standard communication protocol between their $\mathrm{CPs}$ and their central system. Moreover Standard Development Organizations (such as ISO, IEC, and SAE) provide standards addressing connectors, communication, charging topology, safety, and interoperability of EVSEs, and improvements are in progress to achieve a universal 
charging type for EVs. But more work is required in unification of networks of charging stations.

Networks of charging stations are suffering from isolation. This issue can be resolved with a unified communication protocol between service providers to allow cross-network charging. Thus by having a unified network of charging stations with universal charging types, EVOs can charge there EVs regardless of charging type or service provider, consequently it will reduce their range anxiety.

\section{Conclusion}

This paper reviewed the possible solutions to reduce or overcome range anxiety. Providing sufficient charging stations, displaying the $\mathrm{SoC}$ and improving the $\mathrm{SoC}$ estimation algorithms, routing, and providing real-time information about the remaining rage are among the solutions which are suggested by researchers for overcoming range anxiety. Although availability of networks of fast charging stations may reduce range anxiety, accessibility of these networks by EVO is also an important factor. Therefore providing cross-network charging capability to EVOs will bring user satisfaction.

\section{References}

1. C. Y. Chung, "Electric Vehicle Smart Charging Infrastructure," University of California, Los Angeles, Ann Arbor, (2014)

2. B. Römer, T. Schneiderbauer, and A. Picot, "How to Charge Electric Vehicles: A Comparison of Charging Infrastructure Concepts and Technologies," in Driving the Economy through Innovation and Entrepreneurship, C. Mukhopadhyay, K. B. Akhilesh, R. Srinivasan, A. Gurtoo, P. Ramachandran, P. P. Iyer, M. Mathirajan, and M. H. Bala Subrahmanya, Eds. Springer India, (2013), pp. 487-498

3. A. M. Foley, I. Winning, and B. P. Ó Gallachóir, "Electric vehicle: infrastructure regulatory requirements," Proc. Inaug. Conf. Irish Transp. Res. Netw., (2010)

4. P. Dutta, "Coordinating rendezvous points for inductive power transfer between electric vehicles to increase effective driving distance," International Conference on Connected Vehicles and Expo (ICCVE). pp. 649-653, (2013)

5. S. Bai and S. M. Lukic, "Unified Active Filter and Energy Storage System for an MW Electric Vehicle Charging Station," IEEE Transactions on Power Electronics, 28, 12. pp. 5793-5803, (2013)

6. C. H. Dharmakeerthi, N. Mithulananthan, and T. K. Saha, "Planning of electric vehicle charging infrastructure," in IEEE Power \& Energy Society General Meeting, (2013), pp. 1-5

7. J. Dong, C. Liu, and Z. Lin, "Charging infrastructure planning for promoting battery electric vehicles: An activity-based approach using multiday travel data," Transp. Res. Part C, 38, pp. 44-55, (Jan. 2014)
8. J. Chynoweth, C.-Y. Chung, C. Qiu, P. Chu, and R. Gadh, "Smart Electric Vehicle Charging Infrastructure Overview," in IEEE PES Innovative Smart Grid Technologies (ISGT) Conference, (2014), pp. 1-5

9. M. Yilmaz and P. T. Krein, "Review of Battery Charger Topologies, Charging Power Levels, and Infrastructure for Plug-In Electric and Hybrid Vehicles," IEEE Trans. Power Electron., 28, 5, pp. 2151-2169, (May 2013)

10. A. M. A. Haidar, K. M. Muttaqi, and D. Sutanto, "Technical challenges for electric power industries due to grid-integrated electric vehicles in low voltage distributions: A review," Energy Convers. Manag., 86, pp. 689-700, (Oct. 2014)

11. T. Winkler, P. Komarnicki, G. Mueller, G. Heideck, M. Heuer, and Z. A. Styczynski, "Electric vehicle charging stations in Magdeburg," in IEEE Vehicle Power and Propulsion Conference (VPPC), (2009), pp. $60-65$

12. A. Lundström, C. Bogdan, F. Kis, I. Olsson, and L. Fahlén, "Enough Power to Move: Dimensions for Representing Energy Availability," in Proceedings of the 14th International Conference on Humancomputer Interaction with Mobile Devices and Services, (2012), pp. 201-210

13. M. F. Jung, D. Sirkin, T. M. Gür, and M. Steinert, "Displayed Uncertainty Improves Driving Experience and Behavior: The Case of Range Anxiety in an Electric Car," in Proceedings of the $33 r$ Annual ACM Conference on Human Factors in Computing Systems, (2015), pp. 2201-2210

14. J. Ferreira, P. Pereira, P. Filipe, and J. Afonso, "Recommender system for drivers of electric vehicles," $20113 \mathrm{rd}$ International Conference on Electronics Computer Technology (ICECT), 5. pp. 244-248, (2011)

15. M. Rodrigues, S. King, D. Scott, and D. Wang, "Advanced Energy Management Strategies for Range Extended Electric Vehicle." SAE International, (2015)

16. R. van Haaren, “Assessment of Electric Cars' Range Requirements and Usage Patterns based on Driving Behavior Recorded in the National Household Travel Survey of 2009," Solar Journey USA, New York, (2011)

17. Y. Du and G. de Veciana, "Mobile applications and algorithms to facilitate electric vehicle deployment," IEEE Consumer Communications and Networking Conference (CCNC). pp. 130-136, (2013)

18. K. Davis, P. Rowley, and S. Carroll, "Assessing the viability of electric vehicle technologies for UK fleet operators," 48th International Universities' Power Engineering Conference (UPEC). pp. 1-6, (2013)

19. G. Michailidis, "Power allocation to a network of charging stations based on network tomography monitoring," 18th International Conference on Digital Signal Processing (DSP). pp. 1-6, (2013)

20. S. Heath, P. Sant, and B. Allen, "Do you feel lucky? Why current range estimation methods are holding back EV adoption," IET Hybrid and Electric 
Vehicles Conference 2013 (HEVC 2013). pp. 1-6, (2013)

21. L. Gonzalez, H. Novella, E. Gutierrez, J. Ventura, and P. Mogas, "EVIC (Electric Vehicle Intelligent Charging)," 2013 World Electric Vehicle Symposium and Exhibition (EVS27). pp. 1-8, (2013)

22. M. Gharbaoui, B. Martini, R. Bruno, L. Valcarenghi, M. Conti, and P. Castoldi, "Designing and Evaluating Activity-Based Electric Vehicle Charging in Urban Areas," 2013 IEEE International Electric Vehicle Conference (IEVC). pp. 1-5, (2013)

23. J. Tan and W.-H. Lin, "A stochastic flow capturing location and allocation model for siting electric vehicle charging stations," 2014 IEEE 17th International Conference on Intelligent Transportation Systems (ITSC). pp. 2811-2816, (2014)

24. A. G. Bianchessi, G. Cugola, S. Formentin, A. C. Morzenti, C. Ongini, E. Panigati, M. Rossi, S. M. Savaresi, F. A. Schreiber, L. Tanca, and E. G. Vannutelli Depoli, "Green Move: A Platform for Highly Configurable, Heterogeneous Electric Vehicle Sharing," IEEE Intelligent Transportation Systems Magazine, 6, 3. pp. 96-108, (2014)

25. W. He, N. Williard, C. Chen, and M. Pecht, "State of charge estimation for electric vehicle batteries under an adaptive filtering framework," IEEE Conference on Prognostics and System Health Management (PHM). pp. 1-5, (2012)

26. J. C. Ferreira, V. Monteiro, and J. L. Afonso, "Dynamic range prediction for an electric vehicle," 2013 World Electric Vehicle Symposium and Exhibition (EVS27). pp. 1-11, (2013)

27. M. R. Sarker, H. Pandzic, and M. A. Ortega-Vazquez, "Electric vehicle battery swapping station: Business case and optimization model," International Conference on Connected Vehicles and Expo (ICCVE). pp. 289-294, (2013)

28. M. Noro and S. Koizumi, "Present Application and Future Possibilities of Quick Charger for Electric Vehicle," in 1st International Electric Vehicle Technology Conference, (2011)

29. C. Walsh, S. Carroll, and A. Eastlake, "UK ELECTRIC VEHICLE RANGE TESTING AND EFFICIENCY MAPS," in 1st International Electric Vehicle Technology Conference, (2011)

30. P. Weissler, "Staying within range," $S A E$ International, pp. 21-25, (Feb. 2011)

31. H. H. Wu, A. Gilchrist, K. Sealy, P. Israelsen, and J. Muhs, "A review on inductive charging for electric vehicles," IEEE International Electric Machines \& Drives Conference (IEMDC). pp. 143-147, (2011)

32. G. R. Nagendra, J. T. Boys, G. A. Covic, B. S. Riar, and A. Sondhi, "Design of a double coupled IPT EV highway," 39th Annual Conference of the IEEE Industrial Electronics Society, (IECON). pp. 46064611, (2013)

33. S. Lukic and Z. Pantic, "Cutting the Cord: Static and Dynamic Inductive Wireless Charging of Electric Vehicles," IEEE Electrification Magazine, 1, 1. pp. 57-64, (2013)
34. O. C. Onar, J. M. Miller, S. L. Campbell, C. Coomer, C. P. White, and L. E. Seiber, "A novel wireless power transfer for in-motion EV/PHEV charging," Twenty-Eighth Annual IEEE Applied Power Electronics Conference and Exposition (APEC). pp. 3073-3080, (2013)

35. F. Deflorio and L. Castello, "Traffic Modeling of a Cooperative Charge while Driving System in a Freight Transport Scenario," Transp. Res. Procedia, 6, pp. 325-350, (2015)

36. R. Yaqub and Y. Cao, "Smartphone-based accurate range and energy efficient route selection for electric vehicle," IEEE International Electric Vehicle Conference (IEVC). pp. 1-5, (2012)

37. M. Neaimeh, G. A. Hill, Y. Hübner, and P. T. Blythe, "Routing systems to extend the driving range of electric vehicles," Intelligent Transport Systems (IET), vol. 7, no. 3. pp. 327-336, (2013)

38. M. Brandl, H. Gall, M. Wenger, V. Lorentz, M. Giegerich, F. Baronti, G. Fantechi, L. Fanucci, R. Roncella, R. Saletti, S. Saponara, A. Thaler, M. Cifrain, and W. Prochazka, "Batteries and battery management systems for electric vehicles," Design, Automation \& Test in Europe Conference \& Exhibition (DATE), 2012. pp. 971-976, (2012)

39. H. Rahimi-Eichi, U. Ojha, F. Baronti, and M. Chow, "Battery Management System: An Overview of Its Application in the Smart Grid and Electric Vehicles," Industrial Electronics Magazine, IEEE, 7, 2. pp. 4$16,(2013)$

40. G. Carli, A. Shafiei, and S. Williamson, "Advanced Electric Vehicles," in Power Electronics for Renewable and Distributed Energy Systems, S. Chakraborty, M. G. Simões, and W. E. Kramer, Eds. Springer London, (2013), pp. 525-566

41. R. C. Mcllroy, N. A. Stanton, C. Harvey, and D. Robertson, "Sustainability, Transport and Design: Reviewing the Prospects for Safely Encouraging Eco-driving," in Proceedings of the 5th International Conference on Automotive User Interfaces and Interactive Vehicular Applications, (2013), pp. 278284

42. J. B. Gläser and J. O. Berg, "Presentation of a General Purpose Simulation Approach for Enabling the Realization of Electromobility Concepts for the Transportation Sector," in Proceedings of the 2014 Winter Simulation Conference, (2014), pp. 20722081

43. K. Knoedler, J. Steinmann, S. Laversanne, S. Jones, A. Huss, E. Kural, D. Sanchez, O. Bringmann, and J. Zimmermann, "Optimal Energy Management and Recovery for FEV," in Proceedings of the Conference on Design, Automation and Test in Europe, (2012), pp. 683-684

44. C.-H. Lee and C.-H. Wu, "An Incremental Learning Technique for Detecting Driving Behaviors Using Collected EV Big Data," in Proceedings of the ASE BigData \& SocialInformatics 2015, (2015), pp. 10:1-10:5

45. A. Lundström, C. Bogdan, F. Kis, I. Olsson, and L. Fahlén, "EVERT: Energy Representations for Probing Electric Vehicle Practice," in CHI '12 
Extended Abstracts on Human Factors in Computing Systems, (2012), pp. 2141-2146

46. R. Bruninga, "Overlooking L1 charging at-work in the rush for public charging speed," IEEE International Electric Vehicle Conference (IEVC). pp. 1-5, (2012)

47. R. Bruninga and J. A. T. Sorensen, "Charging EVs Efficiently NOW While Waiting for the Smart Grid," IEEE Green Technologies Conference. pp. 1-7, (2013)

48. N. M. A. Aziah, H. M. I. Nizam, S. Ahmad, R. Akmeliawati, S. F. Toha, B. S. K. K. Ibrahim, and M. K. Hassan, "Control strategy of segregation on HVAC energy efficiency as non propulsion electrical hotel load in EV," IEEE International Conference on Power and Energy (PECon). pp. 611-615, (2012)

49. Y. Kondo, H. Kato, R. Ando, T. Suzuki, and Y. Karakama, "To what extent can speed management alleviate the range anxiety of EV?," World Electric Vehicle Symposium and Exhibition (EVS27). pp. 1-8, (2013)

50. M. A. Jeffers, L. Chaney, and J. P. Rugh, "Climate Control Load Reduction Strategies for Electric Drive Vehicles in Warm Weather." SAE International, (2015)

51. P. Guttenberg, S. Chubbock, and T. Gilbert, "A New Philosophy for Hybrid Vehicle Efficiency Optimisation: Simultaneous Optimisation of Component Size and Control Strategy for RealWorld Efficiency in Hybrid and Electric Vehicles," in 1st International Electric Vehicle Technology Conference, (2011)

52. H. E. A. Abis, C. Schwab, R. Kirchberger, "An Innovative Two-Stroke Twin-Cylinder Engine Layout for Range Extending Application," in JSAE/SAE 2013 Small Engine Technology Conference, (2013)

53. J. Yu, Y. Zhang, N. Liu, and B. Wang, "Modeling and control strategy simulation of extended-range electric vehicle," International Conference on Transportation, Mechanical, and Electrical Engineering (TMEE). pp. 829-832, (2011)

54. P. Sharer and A. Rousseau, "Benefits of fuel cell range extender for medium-duty vehicle applications," 2013 World Electric Vehicle Symposium and Exhibition (EVS27). pp. 1-12, (2013)

55. J. J. Escudero-Garzas and G. Seco-Granados, "Charging station selection optimization for plug-in electric vehicles: An oligopolistic game-theoretic framework," in 2012 IEEE PES Innovative Smart Grid Technologies (ISGT), (2012), pp. 1-8

56. I. S. Bayram, G. Michailidis, I. Papapanagiotou, and M. Devetsikiotis, "Decentralized control of electric vehicles in a network of fast charging stations," in 2013 IEEE Global Communications Conference (GLOBECOM), (2013), pp. 2785-2790

57. Wang Meng and Liu Kai, "Optimization of electric vehicle charging station location based on game theory," in Proceedings 2011 International Conference on Transportation, Mechanical, and Electrical Engineering (TMEE), (2011), pp. 809-812 